\title{
Clemente Palma en el afecto y la malquerencia de José de la Riva Agüero y Osma
}

\author{
Juan Carlos Adriazola Silva \\ Instituto de Estudios Histórico Marítimos del Perú \\ adriazola46@yahoo.es \\ Piura-Perú
}

\section{Resumen}

Muchos son los personajes entorno a Ricardo Palma que están estrechamente ligados a su existencia, los cuales continuarán relacionándose entre sí inclusive luego de la muerte del tradicionista acaecido en 1919. En esta oportunidad, nos avocaremos específicamente a dos de ellos: a su hijo mayor, el literato y periodista Clemente Palma; y a su leal y devoto admirador el gran polígrafo peruano don José de la Riva-Agüero y Osma. El primero fue miembro de la generación Modernista y el segundo, parte de la generación del Novecientos o Arielista. Esta comunicación pretende develar los pormenores de esa relación y cuán duradera fue en el tiempo.

Palabras clave: Clemente Palma, José de la Riva-Agüero, Ricardo Palma, generación Modernista, generación del Novecientos o Arielista, literatura peruana del siglo XX.

\section{Abstract}

Many are the characters around Ricardo Palma who are closely linked to his existence and who will continue to relate to each other even after the death of the traditionist in 1919. In this opportunity, we will focus specifically on two of them: his eldest son, the writer and journalist Clemente Palma; and his loyal and devoted admirer, the great Peruvian polygrapher José de la Riva-Agüero y Osma. The first is a member of the Modernist generation and the second, part of the generation of the Nineteenth Century or Arielista. This communication aims to reveal the details of that relationship and how long it lasted over time.

Keywords: Clemente Palma, José de la Riva-Agüero, Ricardo Palma, Modernist generation, generation of the Nineteenth or Arielista, 20th century Peruvian literature. 


\section{Juan Carlos Adriazola Silva (Piura)}

Doctor en Educación por la Universidad Nacional de Piura. Magíster en Investigación y Docencia por la Universidad Nacional Pedro Ruiz Gallo de Lambayeque. Periodista por la Universidad de Piura. Diplomado en Relaciones Internacionales por la Academia Diplomática del Perú. Miembro del Instituto de Estudios Histórico Marítimos del Perú, Centro de Estudios Histórico Militares e Instituto Libertador Ramón Castilla, entre otros. 


\section{Marco biográfico de los personajes de estudio}

Clemente Palma Ramírez ${ }^{1}$ nació en Lima el 3 de diciembre de 1872, hijo del entonces senador por Loreto ${ }^{2}$, don Ricardo Palma Soriano, quien se hallaba consolidando su oficio de escritor y que había publicado ya su primera serie de Tradiciones, conjunto de novísimos relatos que le darán en las décadas siguientes la fama que tanto anhelaba. Su madre fue la ecuatoriana doña Clementina Ramírez Coello ${ }^{3}$. Ricardo y Clementina, ambos con clara ascendencia en la negritud (Adriazola, 2000, p. 12-13; 2018, pp. 383-387), nunca se casaron ni vivieron juntos, por tanto, Clemente quedó bajo la patria potestad del tradicionista, quien lo educó junto con sus otros hijos de la progenie Palma-Román. Esta situación dejó huella indeleble en su vida, lo que forjó en parte su carácter huraño, lacónico y taciturno. Clemente de niño se educó en pequeños colegios particulares y concluyó la secundaria en el Colegio Nacional de Nuestra Señora de Guadalupe. Inició muy joven su servicio al Estado, primero, como «Meritorio» de la Biblioteca Nacional, y luego como «Conservador» de la misma, lo que le permitió leer ingente cantidad de autores nacionales y, sobre todo, universales. Estudió en la Facultad de Letras de la Universidad Mayor de San Marcos, en donde se graduó de Bachiller con la tesis El porvenir de las razas en el Perú, y finalmente de Doctor con Filosofía y Arte. En su época de universitario, fue un fiel seguidor

l Para conocer una biografía más completa de este personaje, véase el artículo Adriazola Silva, Juan Carlos. (2009). «Clemente, el primogénito de don Ricardo Palma». En Aula Palma $\mathrm{N}^{\circ}$ VIII, Lima, Instituto Ricardo Palma de Universidad Ricardo Palma, pp. 213-234.

2 Para mayor esclarecimiento de esta etapa véase el reciente trabajo de Fernando Flores-Zúñiga. Ricardo Palma y la tribuna parlamentaria. El tradicionista senador (1868-1873). Lima, Fondo Editorial del Congreso del Perú, 2019.

3 La relación sentimental entre Ricardo Palma y Clementina Ramírez fue accidental, pues ella casó con Ramón Durand en la Iglesia de San Marcelo de Lima a fines de 1873, luego los esposos Durand partirían a Guayaquil donde fundarían su hogar y no regresarían al Perú por muchos años (Adriazola, 2000, p. 12). 
del Positivismo en materia filosófica; ateo y antirreligioso recalcitrante en asuntos de fe, convicciones que atenuaría con los años. En el campo literario, fue un resuelto seguidor del Modernismo. Practicó el periodismo desde su época escolar, y luego lo abrazó como una de las más grandes pasiones de su vida, privilegiándola incluso por encima de la literatura. Ejerció como Cónsul del Perú en Barcelona (1902-1904). Su primer libro, Cuentos Malévolos (1904), fue prologado en España por el célebre don Miguel de Unamuno. Regresó de Europa casado con María Manuela Schmaltz, con quien tuvo cinco hijos. Políticamente, fue en su juventud fervoroso admirador de Piérola y, más tarde, un anticivilista como su padre; durante el primer gobierno de Augusto B. Leguía (1908-1912) lo combatió con severidad y acritud, lo que llegó a temperaturas mayores después de que el presidente Leguía, para castigarlo como periodista, lo destituyó de su puesto de «Conservador» de la Biblioteca Nacional, motivo por el que su padre debió presentar su renuncia al cargo de Director. Pasado este conflicto, Clemente se asentó luego con su esposa e hijos en una modesta casa del distrito de Miraflores. Clemente Palma combatió con dureza a los gobiernos de Billinghurst y de Benavides. Posteriormente, en un cambio que dejó desconcertados a muchos, Leguía, antes de empezar su segundo gobierno (19191930), incorporó a Clemente Palma en las filas de su partido y promovió su candidatura como Diputado por Lima. Desde entonces Clemente fue transformándose, poco a poco, en un leguiista acérrimo, y, más tarde, volvióse un gran defensor del régimen de la Patria Nueva, llegando incluso a sufrir destierro en Chile (1932-1933). Vuelto a Lima, se dedicó a generar recursos para su subsistencia personal y la de su familia, sacó adelante un proyecto radiofónico con dos hijos varones, Ricardo y Clemente, se dedicó a la corrección de su última novela $X Y Z$ / Novela grotesca, a ordenar los papeles inéditos dejados por don Ricardo y a participar de las sesiones de las instituciones 
culturales a las que pertenecía, entre ellas, la Academia Peruana de la Lengua. Murió de cáncer en el Hospital Arzobispo Loayza el 13 de setiembre de 1946.

José de la Riva Agüero y Osma vio la luz en la capital del Perú el 26 de febrero de 1885. Hijo único del matrimonio de don José Carlos de la Riva-Agüero y Riglos y doña María de los Dolores Carmen de Osma y Sancho Dávila, pertenecientes a la antigua aristocracia virreinal. Por línea directa, descendía del primer presidente del Perú, don José de la Riva-Agüero y Sánchez Boquete. Nació y creció en la rica mansión de la herencia materna, que antaño fuera de los Ramírez de Arellano, en la calle de Lártiga (hoy Camaná $N^{\circ} 459$ ). A los 21 años quedó Riva Agüero huérfano de padre, y desde entonces su familia directa la constituirán su madre, María de los Dolores, y la hermana de esta, Rosa Julia, distinguidas damas herederas de una de las fortunas limeñas más cuantiosas de inicios de la República. Ambas tuvieron decisiva influencia en su formación espiritual. José de la Riva- Agüero estudió desde su infancia en el Colegio de la Recoleta, regentado por los padres franceses de los Sagrados Corazones. Desde pequeño fue un lector impenitente (leía de día y de noche) dentro de su nutrida biblioteca familiar, y libro que no poseía lo buscaba en la Biblioteca Nacional, lo que le llevó a tener una gran cultura universal y peruanista, que adornó con una feliz memoria que asombró a muchos, a tal punto de considerarlo «niño prodigio» (Jiménez, 1966, p.25). Más tarde, inició estudios en la Facultad de Letras y de Jurisprudencia de la Universidad de San Marcos, donde se gradúo de Bachiller con su tesis Carácter de la Literatura del Perú Independiente (1905), y luego de Doctor con la tesis La Historia en el Perú (1910). El primer gobierno de Leguía lo hizo apresar por publicar el artículo de oposición titulado: «La Amnistía y el Gobierno», con lo cual tuvo su primera experiencia política. En 1912, se convirtió en el primer intelectual limeño que recorrió el centro y el sur del Perú, lo que dio como fruto su bello libro 
Paisajes Peruanos. En 1913, se tituló de abogado y se graduó de doctor en Jurisprudencia. A mediados de ese año viajó por el Viejo Continente y representó al Perú en el Primer Congreso de Historia y Geografía Hispanoamericano de Sevilla. Por propia voluntad se exilió en Europa durante el segundo gobierno de Leguía (1919-1930). En este tiempo, se obró en él un cambio de ideas muy radical, pues del liberalismo racionalista y de la postura antirreligiosa que defendió en su juventud, evolucionó a un severo conservadurismo y retornó a la fe católica. Legitimó en España, por herencia directa de su madre y tía, dos títulos nobiliarios: en 1926, el de VI Marqués de Montealegre de Aulestia, y en 1930, el V de Casa-Dávila (Jiménez, 1966, p. 41). Fue célibe y sin hijos. Regresó al Perú pocos días después de la revolución que derrocó a Leguía el 22 de agosto de 1930. Reinició su vida social y pública, y, de 1931-1932, asumió la alcaldía de Lima. Volvió a la Universidad de San Marcos. Presidió el gabinete de 1933 a 1934 como Ministro de Instrucción, Justicia, Culto y Beneficencia, al cual renunció por negarse a firmar la Ley del Divorcio. De 1933 a 1943 presidió la Academia Peruana de la Lengua. Su vastísima y rica producción intelectual lo hizo merecedor del honroso calificativo de «polígrafo». Ostentó muchos cargos institucionales. Entre 1938 y 1940, recorrió varios países y capitales del mundo. A causa de encontrarse su mansión de la calle Lártiga en un proceso de restauración, a consecuencia del terremoto del 24 de mayo de 1940, que dañó a esta y a su casa de verano en Chorrillos, se hospedó en la suite $\mathrm{N}^{\circ} 410$ del elegante Hotel Bolívar, lugar en el que le tocó pagar el tributo común el 25 de octubre de 1944, a causa de un derrame cerebral que lo dejó en coma.

\section{Los Palma y Riva-Agüero: sus primeros encuentros en la Biblioteca Nacional}

Siendo de esferas sociales diferentes y, sobre todo, llevándose de diferencia poco más de doce años de edad, el primer lugar 
de encuentro entre Clemente Palma y José de la Riva-Agüero se produjo en las salas del antiguo edificio de la Biblioteca Nacional del Perú. Pero hay que aclarar que antes que a Clemente, RivaAgüero conoció a don Ricardo Palma, primero, por la lectura de las primeras series de Tradiciones, que seguro le causaron deleite y entretenimiento en la paz de su hogar, y porque siendo escolar, y luego universitario, consultaría frecuentemente los libros de las salas de lectura de la Biblioteca en donde el tradicionista era «Director»y su hijo Clemente ejercía como «Conservador». Oswaldo Holguín, que ha estudiado en profundidad la relación amical entre don Ricardo y Riva-Agüero, ha esclarecido que el primer contacto personal entre ambos fue a mediados de 1893 (antes de cumplir nueve años), cuando Riva-Agüero fue llevado por su abuelo materno don Ignacio de Osma y Ramírez de Arellano a conocer al Director de la Biblioteca y el Archivo Nacional, encuentro este que causó en el pequeño lector una honda y grata impresión (2001, p. 185). Desde aquel tiempo, y por espacio de tres décadas y media, la amistad y vinculación entre don Ricardo y Riva Agüero se mantendría incólume e intensificaría de múltiples formas. Con respecto a la amiticia entre Clemente y José de la Riva Agüero, parece que esta siguió teniendo buen curso en los años siguientes. Por lo menos así lo creía don Ricardo, quien en carta remitida a don Miguel de Unamuno, por entonces Rector de la Universidad de Salamanca, el 19 de diciembre de 1905, le dice:

[Riva-Agüero] hijo único de padres acaudalados, no se le conoce más pasión que el estudio, y jamás se cita su nombre en devaneos de muchacho. Como el médico de su familia le ha prohibido que lea de noche él paga dos lectores de nueve a once de la noche. Lo que había de gastar en teatros, clubs y diversiones lo emplea en libros. Tiene ya muy escogida y copiosa librería. Sus amigos más íntimos son mi hijo Clemente, que ya acaba de cumplir la edad de Cristo 
ha quince días casó en España y que ya es padre de dos chiquillas, y Francisco García Calderón de veintidós años y su compañero de estudios en la Universidad [...] (Kapsoli, 2002, p. 248).

Cuando en 1905, Riva-Agüero editó su tesis Carácter de la Literatura del Perú Independiente, la cual fue celebrada en la Universidad de San Marcos como un verdadero aporte a la cultura peruana, don Ricardo le solicitó a Riva-Agüero varios ejemplares de esa obra para enviar a sus amigos escritores de diversas partes de Hispanoamérica, y de forma especial a los polígrafos españoles don Marcelino Menéndez Pelayo y don Miguel de Unamuno y Jugo, quienes le dedicaron, aparte de las palabras de felicitación y aliento pedido por el tradicionista, estudios críticos en donde asomaban también severas opiniones políticas. Justamente en el estudio elaborado por Unamuno, si bien fue muy honroso y agradecido por Riva-Agüero, este no permitió que se publicara en el Perú la versión original o primigenia, a pesar de la insistencia de los Palma, conocidos por su aversión tanto al expresidente general Mariano Ignacio Prado, quien fugó del Perú en plena Guerra con Chile, como al Partido Civil que agrupaba en sus filas a los hombres más adinerados del país.

Aunque al principio don Ricardo y su hijo Clemente quedaron muy contristados con Riva-Agüero por no permitir publicar en el Perú el estudio del ilustre escritor bilbaíno; al pasar los días, Riva-Agüero intentó convencerlos sobre lo imprudente que hubiese significado para él tomar una decisión no sopesada. Ningún argumento convenció posteriormente a don Ricardo, en cambio, a Clemente, las meditadas palabras de Riva-Agüero, le hicieron cambiar de postura (Kapsoli, 2002, p. 290).

Al final de este asunto, el rector de la Universidad de Salamanca comprendió lo explicado por Riva-Agüero, y siguió manteniendo 
en las décadas siguientes amable correspondencia epistolar con el joven intelectual limeño ${ }^{4}$. En varias de esas cartas, el nombre de Clemente Palma asoma, de tarde en tarde, cuando RivaAgüero escribe a Unamuno que ha cumplido los encargos que le ha pedido realice en su nombre, como el entregar libros a don Ricardo, conseguirle algunos datos de archivo, el envío de una obra de algún escritor peruano en particular, etc. (Kapsoli, 2002, pp. 293 y 298).

\section{Clemente Palma literato y periodista}

El 16 de agosto de 1905 vio la luz pública Prisma, una de las revistas literarias mejor diseñadas y elegantes que se hayan impreso en el Perú durante el primer lustro del siglo XX. La fundaron el fotógrafo de origen portugués Manuel Moral y los periodistas Julio Santiago Hernández y Federico Larrañaga.

Hernández, amigo íntimo de la familia Palma y conocedor de las aptitudes literarias de Clemente, pues este había sido anteriormente cronista teatral en el diario pierolista El País que aquel dirigió, no dudó en invitar al hijo del tradicionista a integrarse en la plana de redactores del nuevo magazine, con el propósito de que se hiciera cargo de una sección de crítica. Clemente Palma aceptó gustoso la invitación y fue así como nació la sección «Notas de Artes y Letras», que tuvo gran éxito entre los lectores, por la versación, buen gusto y hondura de los juicios expresados, al tratar temas vinculados al mundo de las Bellas Artes.

4 Algunas de estas cartas han sido dadas o conocer por Wilfredo Kapsoli, compilador y prologuista del epistolario Unamuno y el Perú, publicado de forma mancomunada por la Editorial Universitaria de la Universidad Ricardo Palma y la Universidad de Salamanca, 2002. 
Al morir don Julio Santiago Hernández en 1906, la dirección de Prisma se encomendó a Carlos Germán Amézaga, pero este vate duraría en el cargo muy pocos meses, ya que falleció repentinamente el 17 de diciembre de aquel año. Es entonces cuando don Manuel Moral, accionista mayoritario de la empresa, designó a Clemente Palma como director de Prisma.

Más tarde, sin embargo, la administración y el consejo de redacción consideraron, en aras de una mayor participación de la revista en la vida pública nacional, cambiar su aspecto formal y sus contenidos. Y fue por esta razón que Prisma tuvo que morir para que naciera Variedades. Clemente Palma, al evocar en 1926 aquellos años de su vida, expresa: «No soy periodista de vocación: era literato, pero, desgraciadamente, en los fértiles campos de la fantasía y del buen decir no se cultivan coles y patatas, imprescindibles para la vida animal del ciudadano de la república de las letras [...]» (Palma, 1926, núm. 933).

Desde que Variedades vio por primera vez la luz pública (el número 1 corresponde al 7-III-1908), Clemente Palma se entregó en cuerpo y alma a su dirección, y permanecerá en este cargo a lo largo de veinticuatro años continuos. La fundación de Variedades es uno de los hitos más trascendentes en la vida de Clemente Palma, pues será en este medio periodístico en donde encuentre su segundo hogar y familia. Hombre recio y con claridad de miras, trabajará tesoneramente, semana a semana, para ubicar a la publicación en uno de los sitiales más importante del periodismo gráfico. Gracias a sus páginas, cargadas de información y fotografías, hoy se puede echar una mirada retrospectiva al Perú de los tres primeros decenios de la vigésima centuria. Y su influencia en la opinión pública nacional de esos años es un hecho que nadie pone en duda. Al ver don Manuel Moral que Variedades alcanzó un rápido éxito entre los lectores, ideó con Clemente Palma la creación de dos nuevas publicaciones. Fue así como surgió el 7 de enero de 1909 La 
Ilustración Peruana y el 7 de abril de 1912 La Crónica, el primer diario tabloide peruano. De ambas publicaciones, Palma será también el director.

$\mathrm{Al}$ entregarse Clemente Palma de lleno al periodismo, muchas fueron las personas que lo animaron a seguir adelante, otras lo criticaron y no pocas lamentaron su alejamiento de la literatura. Uno de sus críticos fue José de la Riva-Agüero y Osma. En 1905, Riva-Agüero, al escribir Carácter de la Literatura del Perú Independiente, había advertido ya las dotes literarias de Palma y, a raíz de ello, había pronosticado que este, en el futuro, sería un escritor que daría gran prestigio a las letras nacionales. Sin embargo, al tomar conocimiento que Palma trabajaba como cronista de Variedades, lamentó mucho que el hijo del tradicionista pusiera de lado su vocación literaria, campo en el que había manifestado excepcionales condiciones desde su temprana juventud, para dedicarse a un oficio más pragmático, realista y controversial como es el periodismo político (Adriazola, 1991, p. 175). Al respecto se lee:

Clemente Palma poseía raras cualidades de cuentista fantástico que hacían de él un descendiente de Hoffman y de Poe; su libro Cuentos malévolos había dado la medida de su talento. Hoy día, el señor Clemente Palma renuncia a la literatura para consagrarse al periodismo político. Tal es el fin de nuestros compatriotas sobre quienes se fundaba las más brillantes esperanzas (Riva-Agüero, 1962 b, p. 453).

Mientras tanto, para Clemente Palma el periodismo cobra un interés creciente; no era para menos, ya que el panorama que se vislumbraba en la escena política durante el primer gobierno de José Pardo es rico en acontecimientos semanales; el civilismo está en todo su apogeo (Basadre, 1971, p. 621). 
Clemente Palma, a diferencia de la mayoría de directores de revistas y periódicos contemporáneos, no estuvo ligado a los grandes grupos de poder económico, sino que representaba a un cierto sector de la intelectualidad limeña, seducido por las técnicas periodísticas modernas que empezaron a llegar de Europa y los Estados Unidos de América en las primeras décadas del siglo XX (Adriazola, 2000, p. 53).

\section{El conflicto de la Biblioteca Nacional}

Clemente Palma, Conservador de la Biblioteca Nacional y, a la vez, director de la revista Variedades, criticaba duramente desde la sección «De jueves a jueves» de esa publicación al presidente Leguía y, de modo especial, al primo de este que a la sazón era ministro de Estado, don Germán Leguía y Martínez. Fue entonces que el mandatario, a instancias de su pariente, decidió castigar al periodista destituyendo al empleado público, mediante una nota fechada el 13 de febrero de 1912. En su reemplazo nombró al joven poeta arequipeño Percy Gibson Moller.

Al recibir el nombramiento de Gibson, don Ricardo Palma reaccionó indignado y, el día 15 del mismo mes, elaboró una nota de respuesta dirigida al Director de Instrucción Pública, en la que informaba al gobierno de su renuncia. La razón que aducía para ello no era otra que el incumplimiento por parte del Ejecutivo del artículo $3^{\circ}$ del Reglamento de la Biblioteca (vigente desde el 4-VII-1884), según el cual el director de la institución era el único capacitado para proponer a los empleados de la misma.

El 22 de febrero, Ricardo Palma replicó al gobierno, argumentando que, si el Ejecutivo estaba satisfecho de sus servicios, solicitaba, de conformidad con el reglamento bibliotecario, se le dé tiempo para buscar un reemplazo a la vacante que dejaba su hijo Clemente. El 
gobierno, en un acto de astucia, se apresuró entonces a derogar el artículo $3^{\circ}$ del Reglamento en el que se amparaba don Ricardo para defender sus fueros. Realizada la derogación del artículo «escudo», el día 27 la Dirección de Instrucción expresó a Palma que había resuelto «mantener el nombramiento expedido el 13 de febrero a favor de don Percy Gibson».

El l de marzo, don Ricardo Palma, tratando de buscar una salida práctica al problema, propuso al gobierno un candidato, el poeta Alberto Ureta. El Ejecutivo desestimó esta acción, pues, según dijo, ya no era facultad del director de la Biblioteca proponer a los conservadores. Palma insistió en su renuncia. Por oficio del 4 de marzo, la Dirección de Instrucción comunicó al tradicionista que, nuevamente, el Supremo Gobierno no acepta la renuncia. El mismo día 4, don Ricardo, en tono altivo, dice al director Pérez Figuerola: «En tal virtud, ruego a Ud. se sirva transmitir al Supremo Gobierno mi insistencia en la renuncia»; era la tercera vez que Palma persistía.

El 6 de marzo, el gobierno resuelve, en vista de la insistencia de Palma, aceptar por fin su renuncia y nombrar en su reemplazo a don Manuel González Prada, «quien debía practicar inventario minucioso y elevarlo al Gobierno» (Basadre, 1983, t. 11, p. 118).

Al saberse en Lima la noticia de que don Ricardo Palma, la figura más destacada de las letras peruanas, había presentado su primera renuncia a la Biblioteca Nacional por defender sus atribuciones de director del atropello de que había sido objeto por parte del gobierno, empezó a promoverse entre los universitarios, escritores y políticos -sobre todo de tendencia antileguiistauna corriente de opinión favorable al tradicionista. Asimismo, se organizó un grupo de personas con el fin de hacer campaña para que ningún intelectual de prestigio asumiera la Dirección de la Biblioteca, en caso de que el gobierno finalmente aceptara la dimisión de Palma. La comisión ejecutiva de aquel grupo la 
lideró José de la Riva-Agüero y la secundaron Felipe Barreda y Laos, José Gálvez, Felipe Sassone, Juan Bautista de Lavalle, Alberto Ulloa, Mariano Ibérico y lo más granado de la juventud intelectual peruana de la segunda década del siglo XX. La idea no era, obviamente, una defensa a Clemente Palma, causante inicial del conflicto. Si bien el conflicto de la Biblioteca empezó como un mero incidente de disciplina burocrática, luego se convirtió en un caso político e ideológico y alineó en un frente, de apariencia literaria, a los enemigos políticos y personales del presidente Leguía y, de otro, a los enemigos doctrinarios de González Prada.

Consumada la renuncia de Palma al cargo de director de la Biblioteca Nacional, la comisión ejecutiva que había dirigido las acciones de respaldo al tradicionista decidió ofrecerle una velada literario-musical para desagraviarlo de la ofensa inferida por el gobierno. Para ello se escogió adrede como local de la velada el Teatro Principal (hoy Teatro Segura), al costado de este recinto y frente a su puerta lateral vivía don Manuel González Prada y su familia. La velada se realizó el lunes 11 de marzo de 1912 y los pormenores de ella fueron reseñados por varias publicaciones de la época y, en especial, por las revistas Ilustración Peruana y Variedades, que dirigía Clemente Palma, las cuales dedicaron muchas de sus páginas a recoger los discursos de los oradores, así como fotografías de los numerosos asistentes. El discurso de Riva-Agüero, en sus principales palabras de encomio, dice:

Sois, señor, como nadie y antes que nadie, encarnación legítima del espíritu de nuestra patria, viva, y sagrada voz del pasado. En vuestra individualidad tomó cuerpo el alma gentil de la raza y por vuestra pluma hemos gustado nosotros mismos plenamente y ha conocido el mundo entero, el encanto del criollismo refinado. En vuestras inmortales tradiciones, evocáis, con magia insuperable, las leyendas de nuestra tierra, las costumbres de nuestros abuelos, los 
recuerdos de nuestra historia, ya sangrienta y trágica, ya pacífica y blanda, sosegada y risueña (Riva Agüero, 1962 b, pp. 358-359).

Si bien es verdad que Clemente Palma en su condición de empleado público debió abstenerse de criticar abiertamente a las autoridades de quienes, en principio, dependía en orden jerárquico, también es cierto que en su condición de ciudadano libre y, sobre todo, de periodista, estaba obligado, por su función pública de informar y, por encontrarse bajo un régimen democrático, a no callar sus opiniones sobre aquellas actuaciones políticas y conducta de los miembros del gobierno que, según su leal saber y entender, no estuvieran basadas en orden a la verdad en el respeto al orden jurídico establecido y orientadas hacia el bien común (Adriazola, 1991, pp. 185-186).

Fue solo hasta el 9 de marzo de 1912, tres días después de que el gobierno aceptara definitivamente la tercera renuncia de don Ricardo, que Clemente rompió el silencio que hasta ese momento había guardado sobre el asunto -como es obvio para no comprometer aún más la posición de su padre ante el gobierno-, mediante una extensa nota editorial aparecida en Variedades en la que agradece al periodista que, bajo el seudónimo de Le Vraie (posiblemente Leonidas Yerovi) había escrito en La Prensa del día 2 de marzo un artículo recriminatorio a todas aquellas personas e instituciones que, en aparente complicidad con el leguiismo, no se habían pronunciado ni a favor ni en contra del ultraje inferido al tradicionista. Este artículo de La Prensa fue también reproducido en Variedades, y llevó por título «Verdades que amargan».

La segunda y última vez en que Clemente se refirió al conflicto de la Biblioteca Nacional en Variedades fue en la edición N ${ }^{\circ} 211$, del 16 de marzo de 1912. En este número, dedicado en gran parte a recoger los detalles de la velada con que la juventud 
universitaria rindió homenaje al autor de las Tradiciones peruanas, Palma fustigó con acritud al responsable intelectual y al verdadero artífice del atropello gubernamental, el canciller Germán Leguía y Martínez, y de paso también a don Manuel González Prada, quien había prestado su concurso para que el Ejecutivo se saliera finalmente con su capricho.

Leguía ante la guerra de insultos que partía de uno y otro lado, no se animó a intervenir personalmente, pues temía que cualquier medida prolongara el escándalo hasta hacerlo interminable. Aunque en Variedades Clemente Palma continuó criticando al régimen leguiista desde su tribuna «De jueves a jueves», el jefe de Estado se abstuvo de clausurar la revista, porque -según consejo de sus asesores- ello hubiera servido de pretexto a sus enemigos políticos para desprestigiarlo aún más en las que eran ya las horas postreras de su primer mandato, y para aniquilar definitivamente las escasas posibilidades de ganar que tenía don Antero Aspíllaga, el presunto candidato del oficialismo en las elecciones presidenciales de 1912.

\section{La vida política en el Perú entre 1911-1919}

En 1911, José de la Riva-Agüero «tuvo su primera aventura política al ser apresado por el régimen de Leguía y puesto rápidamente en libertad como consecuencia de la agitación estudiantil en las calles. El motivo fue su artículo de oposición "La Amnistía y el Gobierno"» (Jiménez, 1966, p. 38). Luego de graduarse de abogado en 1913, Riva-Agüero viajó a Europa vía Nueva York.

Mientras el ambiente de la política interna del Perú se va caldeando cada vez más. Clemente ataca al presidente Billinghurst desde la revista Variedades y, especialmente, desde el diario La Crónica, que junto con La Prensa son los periódicos 
nacionales de oposición. La situación llega a altas temperaturas cuando el Poder Ejecutivo intenta realizar un golpe de Estado disolviendo al Poder Legislativo. Por lo visto, el Congreso no se dejará amedrentar y enfila también sus baterías para defenderse. En esta época, la relación afectiva entre Clemente Palma y RivaAgüero aún está vigente. El tenor de esta carta fechada en Lima, el 10 de enero de 1914, así lo confirma:

Señor doctor don

José de la Riva-Agüero

París.-

Recordado y querido amigo:

Muy grato momento me ha proporcionado su carta del 24 del pasado que me apresuro a contestar. Su carta a mi padre le fue inmediatamente entregada y entiendo que ya le ha contestado.

Juzgo a usted uno de los peruanos más felices porque tiene en sus manos la facultad de alejarse por todo el tiempo que le plazca de la patria y no presenciar las cosas tristísimas y abominables que estamos viendo aquí. El Presidente de la Republica está desenfrenado y ya no hay control ninguno para su espíritu brutal y caprichoso. Usted sabe que ningún mandatario ha tenido mayor apoyo de los partidos políticos que este señor, y que el Congreso ha tenido con él complacencias exageradas. Sin embargo, inesperadamente y en un arranque de fobia ha resuelto dar un peligroso golpe de Estado. [...] Hay una conspiración formidable como usted supondrá y espero que se produzcan acontecimientos graves si llega a salir el decreto de disolución. Tengo datos para creer que el decreto irá acompañado de jornada cívica, de ataques a La Prensa y La Crónica, asesinatos, prisiones, etc. Por otra parte, los miembros del Congreso lanzarán un manifiesto al país en términos enérgicos. [...] 
Cuando reciba usted esta carta ya se habrá producido el suceso y sabe Dios, si estaré escondido, apresado, asesinado o apaleado. Son gajes del oficio. Posible es también que el Presidente se asuste con la enormidad de lo que piensa cometer y más aún con los peligros de la aventura, y se resigne a aguardar hasta julio. Si esto último sucediere le ruego que guarde completa reserva sobre esta carta. Tal es el cuadro pavoroso de nuestra situación política interna con las expectativas de dictadura de un insano y de revolución para entronizar probablemente a otro. [...]

Y termino esta extensa carta, querido amigo, mucho le agradezco su condolencia por el atentado contra La Crónica que no será el último, mientras sea jefe de Estado este demagogo y desalentado señor que nos gobierna.

Gálvez me encarga saludarle. Recuerdos a los García Calderón; mis sinceros respetos a su señora madre y para usted el afecto sincero y hondo de su amigo.

Clemente Palma (Riva-Agüero, 2010, pp. 78-81).

Para acabar con toda esta incertidumbre política que vive el país, el 4 de febrero de 1914, el coronel Oscar R. Benavides, al mando del Ejército, destituye finalmente a Guillermo Billinghurst de la Presidencia y se instala de modo violento en el poder, primero en calidad de presidente de una Junta de Gobierno, y luego como presidente Provisorio. Riva-Agüero sigue en Europa como un atento observador de lo que acontece en el Perú, sin embargo, poco después quedará consternado con el estallido de la Gran Guerra que se inicia en Europa central. Clemente Palma, del otro lado del Atlántico, continúa manteniendo cordial amistad con el polígrafo peruano que reside en Barcelona. Justamente, por esos días, Palma le ha pedido algunos textos de su producción intelectual para publicarlas en la revista Variedades. Riva-Agüero le contesta desde la Ciudad Condal una misiva fechada el jueves 21 de noviembre de 1914, en ella las palabras hacia el 
hijo mayor del tradicionista y su familia están signadas por la calidez:

Señor doctor don

Clemente Palma

Mi querido amigo:

Ayer recibí su atenta carta. Deploro que mis Memorias al Congreso $^{5}$, estén ya comprometidas para el Mercurio y la nueva revista que sacara Gálvez en la Facultad de Letras. Poco pierde usted, pues, son dos estudios farragosos y poco originales. Pero le remitiré a usted, con mucho gusto, mi discurso en el Congreso, que es breve, una conferencia también corta, sobre Ocopa y las misiones franciscanas; y en vez del pueblo español, que me inspira poco nuevo que decir, unas impresiones de Mallorca.

Contésteme usted siempre a este hotel Ritz de Barcelona, donde permaneceré hasta el 6 de diciembre, indicándome dónde debo enviarle esos escritos.

Póngame a los pies de su señora, y con recuerdo de todos los míos para ella, usted y sus hijos, me repito su muy cordial amigo que le estrecha la mano.

José de la Riva-Agüero (Riva-Agüero, 2010, pp.81-82).

Riva-Agüero retornó al Perú a fines de diciembre de 1914. Encontró el medio político lleno de inquietudes y esperanzas, particularmente entre la juventud. Gustaba por entonces convocar a los nuevos escritores e hizo de su estudio y casas en el centro de Lima y en Chorrillos generosos cenáculos. En esta época contó con la colaboración de Abraham Valdelomar y Manuel Beltroy como secretarios. Lo frecuentaban profesionales

5 A mediados de 1913, Riva Agüero ya titulado de abogado y luego graduado de doctor en Jurisprudencia, viajó a Europa, en donde representó al Perú en el Primer Congreso Hispanoamericano de Historia y Geografía, en Sevilla. 
talentosos, dirigentes sociales y periodistas de polendas (Jiménez, 1966, pp. 39-40). Clemente Palma, lo visitó varias veces en la calle de Lártiga, y compartió su mesa; y hasta donde es posible afirmar, Riva Agüero debió también haberle devuelto a Clemente las visitas tanto en su oficina de la Casa Editora Moral. La Crónica y Variedades, ubicada en el Jirón Carabaya (calle Pando $\mathrm{N}^{\circ} 758$ ), como en su mesocrático hogar en la calle Bellavista de Miraflores (Riva-Agüero, 2010, p. 83).

Las elecciones presidenciales convocadas por Oscar R. Benavides en 1915, dan como ganador a José Pardo y Barreda, intelectual, diplomático, hijo del fundador del Partido Civil don Manuel Pardo y Lavalle. El año anterior a su elección había retornado de Europa y seguidamente fue elegido rector de la Universidad Nacional Mayor de San Marcos. Cargo que dejó para asumir su periodo gubernativo el 15 de agosto de aquel año. Empezó su gestión con los mayores auspicios de desarrollo y progreso nacional, sin embargo, en las Cámaras le hace fuerte oposición los partidarios del derrocado Billinghurst y de Leguía, quien había gobernado el Perú de 1908-1912. Clemente Palma critica severamente desde su crónica «De jueves a jueves» de Variedades y en reiterados editoriales de La Crónica, tanto a billinguristas como a leguiistas (Adriazola, 1991, p. 178). En este tiempo, Riva-Agüero, apoyado por los jóvenes que lo seguían, decide fundar el Partido Nacional Democrático,

cuyo programa redactó. Sus objetivos sin ser radicales aspiraban a ser una renovación moral y doctrinaria de la política peruana; pero fue incomprendido tanto por la clase gobernante estrecha y rutinaria, como por los sectores rebeldes, cuya protesta exacerbada no recogía (Jiménez, 1966, p. 40).

¿Qué llevó a Riva-Agüero a la fundación del Partido Nacional Democrático? Según Enrique Chirinos, con su habitual capacidad de síntesis, responde: 
El propósito es el de habilitar una tienda en la que pueden darse la mano los jóvenes que han perdido el Partido Demócrata, al morir Piérola, como José María de la Jara o como José Gálvez, con lo jóvenes que, como el propio Riva Agüero, siendo de estirpe civilista, estiman ya históricamente caduco al Partido Civil. En 1917, Lima debe elegir diputados, el Partido Nacional-Demócrata se abstiene. Riva Agüero explica, con cierto desdén, que él y los suyos no piensan en hoy. Piensan en el mañana. No son políticos. Tal es la lógica deducción de Luis Fernán Cisneros en La Prensa, quien los apoda «Futuristas» (1982, p. 415)

\section{El leguiismo, la manzana de la discordia}

Ante el panorama adverso de la política, Riva-Agüero decidió autoexiliarse en Europa, estancia que duró los once años de la dictadura leguiista. Vivió de preferencia en Roma, pero se desplazó reiteradamente a otros países del Viejo Continente, en especial a la Península Ibérica. Hizo allí la existencia señorial a la que estaba acostumbrado, pero sin boato ni futileza. Legitimó, por herencia directa de su madre y de su tía, respectivamente, el marquesado de Montealegre de Aulestia en 1926 y el de CasaDávila en 1930. Usó el título del primero de ellos mientras residía en Europa (Jiménez, 1966, pp. 41-42). Nunca dejó de escribir, e investigó los asuntos de la patria en diversos archivos históricos de Roma, Viena, París, Madrid y Sevilla, lo que le proporcionó un bagaje amplio de información que dio gran solidez a sus investigaciones posteriores.

Caído el régimen de la Patria Nueva, Riva-Agüero regresó al Perú el 28 de agosto de 1930. Se sintió animado en los años siguientes a participar de los asuntos públicos. Fue alcalde Lima (1932-1933), como lo habían sido en el pasado muchos de sus aristocráticos ascendientes. Y en corto período aceleró 
muchas obras públicas de tipo habitacional y de mejora de la higiene ciudadana. De 1933 a 1934, Riva-Agüero presidió el gabinete bajo el régimen de Oscar R. Benavides como Ministro de Instrucción, Justicia, Culto y Beneficencia, cargo al que finalmente renunció por negarse a firmar la Ley del Divorcio, por considerarla anticatólica.

Cuando Riva-Agüero no se hallaba inmerso en sus propios proyectos políticos, embarcábase en el de otros, luego de sopesarlos en su fuero interno como justos o pertinentes para el bien de la República. Es entonces que decidía apoyarlos sin escatimar esfuerzos ni recursos económicos, con tal de lograr los fines deseados. Tal sucedió, en 1936, en las elecciones convocadas por el gobierno al concluir el periodo que el Congreso designó a Oscar R. Benavides para completar la gestión gubernativa que no concluyó el presidente Sánchez Cerro por causa del magnicidio de que fue víctima. En esta ocasión, Riva-Agüero apostó por la candidatura presidencial de su colega sanmarquino Manuel Vicente Villarán. Otros candidatos en la justa electoral fueron Jorge Prado y Ugarteche, Luis A. Flores -jefe de la Unión Revolucionaria-y Luis Antonio Eguiguren. La inscripción de Víctor Raúl Haya de la Torre ante el Jurado Nacional de Elecciones fue rechazada por considerarse que el APRA, partido que lo respaldaba oficialmente, era una organización de carácter internacional y, según el artículo 53 de la Constitución vigente, eso estaba prohibido (Chirinos, 1982, p. 496). Sobre su posición personal y el momento político que vivía el Perú, Riva-Agüero, en carta datada en Lima el 4 de septiembre de 1936, comenta a su amigo Francisco García Calderón, que reside en París:

Como sabrás, soy de los más decididos partidarios de la candidatura Villarán, y de hecho hago por ella cuanto está a mi alcance, sin excusar sacrificios de tiempo y dinero. Pero las cosas van muy mal, y no he ocultártelo a ti que recibirás 
esta carta en vísperas de la votación, y así mis impresiones no podrán desanimar a nadie. El favor oficial se inclina a Prado, el Director de Gobierno, sus dependientes y acólitos, y los periódicos estipendiados, de manera cínica combaten a nuestro candidato. Si se acepta la legalidad de las candidaturas apristas, corremos el grave peligro de un triunfo de Haya. En el caso contrario, revolución; y persistiendo en las votaciones mismas, por la renitencia de Amadeo de Piérola, que está chocho, y de los leguiistas que siguen tan perversos como siempre, junto con el exclusivismo insano de Flores y su pseudo fascista grupo, lo más probable es la anulación de las elecciones. Como aquí todos me toman por víctima propiciatoria de los pecados de los demás, me culpan, por haberme negado hace un año a acudir a una concentración general. La acriminación es tan estúpida como otras que suelen dirigirme. Ni tenía yo entonces grupo formado con que acudir legítima ni decorosamente, ni en caso alguno podía fiarme a una abrumadora mayoría de adversarios, que me habrían uncido a cualquier solución vergonzosa, como la de Prado u otras análogas, pues era obligatorio someterse de antemano a la dirección mayoritaria, repugnante a nuestros intereses, ideas y decoro. Hemos preferido una coalición limitada de derechas; y si en ella sucumbimos, por lo menos habremos salvado, con honor, el lejano porvenir. Villarán piensa de la misma manera: combate por deber cívico, para mantener, contra la desvergüenza de unos y la indiferencia o cobardía de otros, una insignia de honradez y de orden, que servirá para las reagrupaciones de mañana. Yo, aunque en muy segunda fila, sigo siendo blanco de los más vehementes ataques, lo que me enorgullece porque me muestra que para algo sirvo. Leerás el infame comunicado que redactaron contra mí los leguiistas Clemente Palma y Ernesto Denegri. Ambos me deben positivos favores. Contribuí a abreviarles la prisión y evitarles que se les duplicara el destierro. En mi 
refutación a sus impúdicas mentiras he explicado porqué acepté en 1928 la cátedra honoraria de la Universidad, y a tal propósito cito tu nombre, pues recordarás que me entregaste la carta de [Guillermo] Salinas [Cossío] que me aconsejaba la aceptación, y hablamos de ella (Riva-Agüero, 1999, pp. 753-754).

El mismo día que Riva-Agüero escribió el texto anterior, diose tiempo para redactar otra misiva para el hermano menor de Francisco, el literato y diplomático Ventura García Calderón Rey, quien cumplía funciones como ministro plenipotenciario en París. En esta epístola, Riva-Agüero le comunica a Ventura, los acontecimientos políticos que están ocurriendo en ese ínterin en el Perú; acontecimientos que, con mayor amplitud, le ha hecho saber también a «Pancho» (hipocorístico con que Riva-Agüero trataba en confianza a Francisco). Asimismo, en el tenor de la carta a Ventura, se puede leer los furibundos epítetos que Riva-Agüero lanza contra sus adversarios políticos, entre ellos a Clemente Palma. Y, de paso, elabora una crítica sobre las tendencias literarias por las que se inclinan los escritores peruanos de aquellos días. Todo este conjunto de ideas y conceptos vertidos, son una muestra interesante para conocer cómo estaba entonces amoblada la cabeza del Marqués de Montealegre de Aulestia. El remitente dice:

Mi muy querido Ventura:

Hace mucho tiempo que deseaba escribirte para felicitarte y darte las gracias por tu nuevo libro Aguja de Marear. [...] Tu frasear es a la vez tan rico, tan conciso, pintoresco y musical, que lo saboreo como una golosina. Mis aplausos por tu ataque a los obscuristas o negongorinos, de que hay peste en el Perú, contemporáneo y aprista. La juventud revolucionaria no sólo escribe muy mal, sino que piensa y ejecuta peor. Son, como los populistas de tu Francia, antiliteratos, enemigos del 
espíritu. Blasfeman de los maestros de nuestro tiempo, de Rubén y de Rodó, los semidioses de nuestra juventud, fauno inspirado el primero y el otro iniciador platónico de nuestras elevaciones de alma. A Dios gracias, todavía nosotros creemos en el arte por el arte, en la que la hermosura vale por sí. Dios, que es lo Absoluto, es por lo mismo belleza. Los nuevos izquierdistas, en pésimas copias de mimeógrafo, no hablan sino de arte proletario. En el fondo, lo que quieren no es sino robar, principiando su explotación contra los propios campesinos y obreros. De aquí deducirás cuales son las amenazas de mejicanización futura que el movimiento aprista y socialista encierra. Es próximo el riesgo de anarquía política. Verosímilmente no pasarán muchas semanas sin que te llegue la noticia de una de nuestras consuetudinarias revoluciones. Sigo siendo, no sin íntimo e intenso orgullo mío, el más impopular, calumniado y ultrajado de los políticos. Los que me atacan son aquellos a quienes he servido y alabado, por ejemplo, tu querido amigo y vecino mío, el zambo Víctor Maúrtua, que en recompensa de haber yo accedido a sus ruegos y haberle entonado una laudatoria para que no lo desairaran en cierta candidatura a La Haya [Holanda], me llama socarronamente Marqués cuando me encuentra, con lo que no he podido ahorrarle ante sus contertulios algunas fulminantes observaciones sobre su casta y su conducta en La Habana. El otro mulato enemigo es el infame Clemente Palma, en correspondencia a lo mucho que he alabado a su padre y hermana difuntos, y haber sufragado parte de sus exequias de esta en Lima. No me ataca menos el bellaco Rafael Larco, con su jauría de perros sarnosos de La Crónica. Afuera, el más viperino, es Luis Alberto Sánchez, que se decía en otro tiempo mi amigo y a quien saqué de prisión cuando Sánchez Cerro (Riva Agüero, 1999, pp. 814-815). 


\section{Riva Agüero y Clemente Palma en la Academia Peruana de la Lengua}

La Academia Peruana de la Lengua, creada a iniciativa de don Ricardo Palma en 1887, tuvo una vida fructífera por varios años hasta que, poco a poco, cada uno de sus doce académicos fundadores empezaron a fallecer, quedando solo vivos el tradicionista y don Emilio Gutiérrez de Quintanilla. Por esta razón, la Corporación limeña entró en receso por dos años, motivo por el cual don Ricardo Palma decidió reestablecerla en 1917. Para ello pensó que elementos valiosos de las jóvenes generaciones debían irse incorporando para trabajar en pro del prestigio de la institución ${ }^{6}$, fue así que pensó que José de la Riva-Agüero y Osma sería un candidato idóneo. Al respecto, Aurelio Miró Quesada |expresa:

[Ricardo] Palma empezó a proponer, carta tras carta, a los nuevos integrantes. El primero fue José de la Riva-Agüero, que acababa de pronunciar su magistral Elogio del Inca Garcilaso, y a quien señaló, con mirada profética, como «el llamado a organizar la nueva Academia peruana». Y luego otros brillantes nombres de escritores, con toda la lozanía moceril de la época (1967, p. 34)

La esperanza de don Ricardo Palma, acerca del liderazgo que cumpliría José de la Riva-Agüero en la Academia, solo se haría realidad 17 años después de lo proyectado. Riva-Agüero

6 En 1917, Ricardo Palma incorporó junto con Riva-Agüero a Óscar Miró Quesada, Javier Prado y Ugarteche, Juan Bautista de Lavalle, Víctor Andrés Belaunde, José María de la Jara, Alejandro Deustua, José Gálvez, Francisco García Calderón Rey, Luis Felipe Villarán, Enrique A. Carrillo, Luis Fernán Cisneros, Felipe Barreda y Laos, Enrique Castro Oyanguren. Pertenecían a la Academia Peruana, además de los antedichos, Mariano H. Cornejo y Pedro José Rada y Gamio, quienes fueron incorporados directamente por la Real Academia Española, en Madrid. 
fue elegido director de la Academia Peruana recién en 1934 y sería su principal mecenas durante una década exacta. Don Aurelio Miró Quesada, refiriéndose al espíritu que Riva-Agüero imprimió a la Corporación limeña desde el principio de su gestión, dice que este fue el de

un nuevo espíritu de laboriosidad y entusiasmo, e inició la costumbre de las sesiones públicas anuales el 23 de abril, aniversario de la muerte de Cervantes, que él mismo solemnizó más de una vez con sus discursos capitales sobre la repercusión del autor del Quijote en nuestra literatura virreinal y el elogio de los poetas peruleros en la primera obra de Cervantes (1967, p. 37).

Por su parte, Jiménez Borja añade:

Dirigía la Academia Peruana de la Lengua y le daba, junto con su anfitronía de la Casa de Lártiga, ejemplo de actividad al ofrecer buen número de doctas y galanas disertaciones que en 1935 reunió en el libro Discursos académicos (1966, p. 46).

Con respecto a la forma cómo funcionaba en el Perú la Academia de la Lengua y cuántos académicos acompañaban a Riva-Agüero en su gestión, el mismo polígrafo informa en una carta dirigida al Secretario de la Academia Argentina de Letras, Gustavo Adolfo Martínez Zuviría, el modo de trabajo, el lugar y los nombres específicos de las doce personalidades ${ }^{7}$, que conforman la Corporación limeña a mediados de 1935 (Riva Agüero, 2005, pp. 216-217).

7 A los doce miembros iniciales que conformaron la Academia Peruana durante la dirección de Riva-Agüero, vinieron a incorporarse luego Jorge Basadre, Honorio Delgado, Guillermo Hoyos, Mariano Iberico, José Jiménez Borja, Enrique López Albújar, Raúl Porras Barrenechea y el Rvdo. Padre Rubén Vargas Ugarte. 
De acuerdo al Estatuto fundacional de la Academia Peruana de la Lengua de 1887, redactado por el propio Ricardo Palma y vigente aún durante la gestión de Riva-Agüero (19341944), -gestión que Aurelio Miró Quesada ha calificado con toda propiedad como la «Tercera Etapa» (1967, p. 37) de vida institucional-, para ser considerado un verdadero académico (entiéndase de número, titular o de sillón), aparte de contar con los votos necesarios en un sufragio, residir en Lima y hacer los aportes económicos indicados, era necesario leer un discurso de incorporación tal como se hacía en la Real Española. De no cumplir con este requisito, el elegido solo mantendría en la Academia condición de «electo», lo que significaba que todavía no había cumplido a cabalidad con los Arts. $19^{\circ}$ y $20^{\circ}$ del Estatuto (Academia Peruana de la Lengua, 1967, p. 63).

Al parecer, los tiempos prescritos por el Estatuto de la Academia Peruana de la Lengua no se cumplieron en el caso de Clemente Palma como debió ser, en principio, pues transcurrido casi un año después de su elección, el hijo mayor del tradicionista seguía sin haber leído el llamado «discurso de incorporación» (Riva-Agüero, 2005, p. 348).

A fines de 1935, estando próxima a concluirse la decimosexta edición del Diccionario de la Real Academia Española (DRAE), el director de la Docta Corporación matritense, Menéndez Pidal, remitió una comunicación a todas las Academias de la Lengua de los países americanos para que estas enviaran de forma oficial la nómina actualizada de sus académicos, y de este modo aparecieran todos con sus nombres y apellidos en las páginas liminares del mencionado lexicón, como había sido tradición desde la primera edición del Diccionario en 1780 para el caso de los académicos españoles, y a partir de la duodécima edición de 1884 para el caso de las académicos correspondientes de América. Al no haber presentado un discurso de incorporación como mandaba el Estatuto, Riva-Agüero decidió no enviar aún 
el nombre de Clemente Palma para que apareciera en el listado oficial de los académicos peruanos, según se puede verificar en la mencionada edición aparecida el 15 julio de 1936, a tan solo dos días del inicio de la Guerra Civil Española, conflicto bélico que vino a afectar también la vida ordinaria de la Academia, que entró por algún tiempo en receso. Los académicos españoles de tendencia franquista empezaron entonces a cavilar la idea de que era necesario hacerle algunos cambios formales a la edición decimosexta del Diccionario de la Lengua Española, aunque conservó el íntegro de vocablos o entradas del cuerpo léxico. El lanzamiento de esta decimosexta edición «modificada» apareció cronológicamente en 1939, llamado «Año de la Victoria». Es interesante aclarar que entre los cambios de forma que trajo esta publicación, se omitió las listas de todas las Academias de la Lengua de los países americanos. Por esta razón, el nombre de Clemente Palma y el de sus colegas en la Academia Peruana de la Lengua no aparecen en la mencionada edición del DRAE de 1939. El tiempo fue transcurriendo y a hasta donde es posible afirmar, Clemente Palma nunca leyó un discurso de incorporación (Riva-Agüero, 2003, p. 919) durante el directorio de Riva-Agüero, quien murió en Lima el 25 de octubre de $1944^{8}$. Parece confirmar este aserto, el hecho de

8 La edición decimoséptima del DRAE (1947) considera a la Academia Peruana de la Lengua como acéfala, pues ya no trae el nombre del Sr. D. José de la Riva Agüero como presidente de la misma, debido a su óbito acaecido en Lima el 25/10/1944. Sí, en cambio, el de los dos cargos jerárquicos más importantes que le seguían en orden descendente: José Jiménez Borja, secretario; y Juan Bautista de Lavalle, censor. Continuaban cuatro miembros de número más: Víctor Andrés Belaunde, Óscar Miró Quesada, José Gálvez y el R. P. Rubén Vargas Ugarte. Luego once académicos en la condición de «electos»: Manuel Vicente Villarán, Clemente Palma, Raúl Porras Barrenechea, Guillermo Hoyos Osores, Enrique López Albújar, Honorio Delgado, Jorge Basadre, Mariano Iberico Rodríguez, Francisco García Calderón, Felipe Barreda y Laos y Luis Fernán Cisneros, en total 17 académicos, de los 18 que debían ser según lo normado y vigente entonces. Cfr. Real Academia Española (1947). Diccionario de la Lengua Española. Madrid, Espasa Calpe, p. xv. 
que, en la decimoséptima edición del Diccionario de la Real Academia Española, publicada en el año 1947, aparece ya el nombre y apellido de Clemente Palma como miembro de la Academia Peruana de la Lengua, pero con la calificación de académico «electo» ${ }^{9}$. Es más, esta sería la única vez que el hijo mayor del tradicionista ostentaría dicho honor en las páginas iniciales de la magna obra del español universal, ya que, al haberse extinguido su vida el 13 de septiembre de1946, la decimoctava edición del DRAE del año 1956 ya no consideró más su nombre.

Con la distancia del tiempo, hoy se puede inferir que la candidatura de Clemente Palma para ser elegido miembro de número de la Academia Peruana de la Lengua, debió ser incómoda para Riva Agüero; no porque él dudara de que el hijo mayor del tradicionista carecía de calidades literarias para ser parte de la docta Corporación limeña -asunto que para el director y los otros colegas académicos jamás estuvo en tela de juicio-, sino porque, en su fuero interno, desconfiaba de él y hasta cierto punto lo aborrecía por su activa participación política durante la dictadura leguiista. Por otra parte, no puede negarse que la época del leguiismo había causado en el espíritu de Riva Agüero un hondo resentimiento por los desmesurados $\mathrm{y}$ viles ataques recibidos contra su persona desde varios frentes, lo que lo obligó pronto a autoexiliarse en Europa durante el Oncenio. De allí que la figura de Clemente Palma, como defensor periodístico de Augusto B. Leguía a través de la revista semanal Variedades y del diario La Crónica, y como escudero político

9 Esta calificación de académico «electo» no le impidió el ejercicio cabal de sus responsabilidades hacia el interior de la Academia Peruana de la Lengua. Incluso Riva-Agüero le encargó la tarea de contestar discursos de incorporación de nuevos recipiendarios, en especial, el caso de su compañero de generación Enrique López Albújar. Sobre este asunto específico existe amplia correspondencia epistolar, vid: Riva-Agüero, 2003, vol. II, pp. 907-909, 911 914, $918-923$. 
del gobernante en el Congreso en su calidad de diputado por Lima, era de por sí irritante y molesta para el gran polígrafo peruano, que había dejado de estimarle, sobre todo, por dicha razón. Aunque también asoma en muchas de sus expresiones epistolares, calificativos racistas por el color de la piel del hijo del tradicionista, vinculado sanguíneamente a la negritud.

Para Clemente Palma la actitud de rechazo tomada por RivaAgüero era comprensible, pues bien sabía cómo pensaba este en materia política e ideológica, y lo respetaba. Sin embargo, debe destacarse que Palma era también consciente de que, desde mucho tiempo antes, había tomado un camino firme y resuelto en defensa del régimen de la Patria Nueva, y fue consecuente con ese pensamiento hasta el final de su vida, esto es, no renegó de él, ni en los días aciagos de persecución contra los leguiistas que vinieron tras la prisión de Leguía en el Panóptico, ni luego cuando el leguiísmo fue liquidado definitivamente del espectro político peruano en las dos décadas siguientes.

A diferencia de Clemente, su hermana Angélica Palma, sí continuó cultivando excelentes relaciones amicales con José de la Riva-Agüero ${ }^{10}$. A tal punto que este llegó a calificarla como «mi mejor amiga intelectual» ${ }^{11}$, y cuando esta murió

10 Cuando fue derrocado el régimen de Leguía (22/8/1930) por la revolución de Sánchez Cerro, Angélica Palma encontrábase residiendo en España, a donde viajó para organizar la edición de Tradiciones peruanas completas de su padre. Estando una vez de vuelta de París a Madrid, ciudad esta en la que se había establecido con sus hermanas, Angélica Palma escribe a Riva-Agüero, el 16 de noviembre de 1930: «El régimen que acabamos de padecer deshizo y corrompió tanto, que el considerar las dificultades de una verdadera reacción saludable me enturbió un poquito la alegría producida por el triunfo de la revolución; también me inquietó desde el primer momento al calcular las consecuencias que la nueva situación traería para Clemente, cuya afiliación en el leguiismo fue para mí sumamente penosa, como recordará usted que le dije en Barcelona» (Riva Agüero, 2010, p. 55).

11 Esta frase es parte del amplio discurso fúnebre que don José de la Riva Agüero llegó a leer en el entierro de Angélica Palma, el mismo que fue incluido más 
repentinamente en la ciudad de Rosario (Argentina) el 6 de septiembre de 1935, Riva-Agüero pagó en Lima parte de sus funerales. Doce días después de este óbito, el director de la Academia Peruana de la Lengua escribió a su gran amigo y futuro albacea especial, don Miguel Lasso de la Vega y López de Tejada, IX Marqués del Saltillo y Miembro de Número de la Real Academia de la Historia de Madrid, lo siguiente:

[...] Te hablaré de la muerte de nuestra amiga Angélica Palma, nuestra compañera de excursiones, en ya lejanos días, de Segovia y Mallorca. Recuerdo como nos chanceábamos de ella y sus silbidos, y ahora su desaparición en la remota Argentina, me ha producido verdadero y profundo pesar. Siempre me mostró amistad lealísima; y no son muchos los amigos como tú y ella: los cuento con los dedos de una mano, y algunos ya están en el otro mundo. Se fue a dar sus conferencias contentísima, por el crédito que de ellas le redundaba pues mis fríos paisanos no le hacían mucho caso, que nadie es profeta en su patria, y por las ganancias que se prometía, porque disminuida, en una mitad la pensión que le correspondía por los servicios de su padre, vivían en verdadera estrechez. Mientras fui ministro las restablecí en el goce íntegro de aquella mediana pensión. Mis sucesores fueron menos generosos. [...] El hermano literato que subsiste es un negro desalmado y canalla; y necesito recordar continuamente a su padre y a su hermana para poderlo sufrir en la Academia y la política (Riva Agüero, 2003, p. 332).

En 1939, estando Riva-Agüero de visita en la capital del Japón, llegó a sus oídos un rumor preocupante sobre Clemente Palma:

tarde como parte del libro de homenaje que editó en 1937 la Sociedad Amigos de Palma con el título de Angélica Palma, gracias al auspicio económico del ilustre polígrafo limeño, p. 27. 
sus colegas académicos peruanos supuestamente lo habrían elegido para el cargo de secretario de la Academia Peruana de la Lengua, y en posesión de ese cargo, este la habría declarado oficialmente en receso. Este rumor alarmó y, al mismo tiempo, disgustó muchísimo a Riva-Agüero, quien era director en funciones de la Academia. Por ese motivo, Riva-Agüero escribió el 21 de enero de ese año a su secretario personal en Lima, don Eduardo Indacochea, a quien, después de solicitar una serie de encargos de envío de libros de su autoría, mandar publicar artículos suyos en El Comercio y, en su representación, visitar a la viuda e hijas casadas del entonces fallecido académico peruano Enrique Castro Oyanguren, le expresa furibundo lo siguiente:

Explíqueme quién y con qué derecho ha tenido en la Academia la infeliz o penosa ocurrencia de elegir como Secretario a Clemente Palma, pues está en receso por causas graves, yo soy su director y pese a quien quisieran con ese nombramiento a obligarme a renunciar al cargo y dejarlo, renunciando al discurso de orden, Palma ni siquiera se incorporaría. Acláreme el asunto y reclame con vigor sobre ese desaire. Quiero saber quién me lo hace (Riva-Agüero, 2000, pp. 320-321).

En carta similar, esta vez datada en Roma el 15 de junio de 1939, Riva-Agüero insiste a Indacochea sobre el encargo ya formulado:

Instrúyame usted qué pasa con la Academia de la Lengua y con la insólita incorporación de Clemente Palma como Secretario, conculcando mi autoridad y las poderosas razones que tuvo para dejar la Academia en receso. Pienso protestar en España, y pedir que me autoricen, para evitar ese despojo de mis legítimas facultades de Director (RivaAgüero, 2000, p. 325). 
Finalmente, se llegó a la conclusión de que la supuesta «acción conculcatoria» de Clemente Palma contra el director de la Academia Peruana de la Lengua, dada como noticia a Riva- Agüero mientras este se hallaba fuera del Perú, fue simplemente una información que no se ajustaba a la verdad. ¿Quién la emitió? ¿Qué razones tuvo? ¿Qué efecto deseó causar? En el presente se carece de fuentes documentales para responder puntualmente las dos primeras preguntas. La tercera pregunta quizá pueda responderse indicando que la persona que generó la desinformación desde Lima sí tenía claro conocimiento de la malquerencia que José de la Riva-Agüero guardaba por Clemente Palma, y lo único que hizo fue lanzar algo de «combustible» al fuego para de este modo avivar la llama de esa antipatía o mala voluntad que don José no siempre sabía disimular con propios ni extraños.

\section{El desterrado político busca consuelo en el viejo amigo}

Clemente Palma, por su estrecha vinculación política con el leguiismo, fue desterrado a Chile a inicios de 1932 por el gobierno de Sánchez Cerro. Esta situación penosa en la vida del hijo mayor del tradicionista, está signada esencialmente por la ausencia física de sus seres queridos y por la escasez de los recursos económicos que golpearon permanentemente su estado de ánimo en los largos meses que residió en la capital del Mapocho. Palma no por ello se dejó vencer por las tribulaciones ni cortó la comunicación con su esposa e hijos, hermanos y amigos, así lo testimonian un sinnúmero de epístolas de ida y vuelta de ese periodo de su vida. En carta fechada en Santiago, el 2 de noviembre de 1932, Palma le expresa a Riva-Agüero:

Muy apreciado amigo:

Por carta de mi hermana he sabido que en alguna ocasión reciente tuvo usted la bondad de recordarme con afecto 
y decirle que con interés haría usted lo que estuviera a su alcance para servirme con su influencia personal en lo que pudiera necesitar. No quiero dejar pasar más tiempo para agradecerle la amistosa disposición de espíritu en que se encuentra para con su viejo amigo y admirador. Me aprovecharé de su buena voluntad cuando llegue el caso; y por ahora solo me limitaré a darle la lata, echando un palique con usted sobre el tema palpitante y doloroso que me imagino preocupa a todos los peruanos allá, como preocupa a los peruanos de acá.

En meses pasados escribí a mi esposa insinuándole que intentara el proponerle a usted una operación comercial con el objeto de arbitrarse algunos soles para poder venirse con mis hijos a compartir conmigo las penalidades del destierro a que me tiene condenado su amigo Sánchez Cerro. Se trataba de ofrecerle en venta un terrenito que poseo en Miraflores por un precio moderado; pero, aunque mi esposa me manifestó al principio la intención de hacerle la propuesta, no llegó a hacérsela, entiendo que, porque sensatamente juzgó que la época no era oportuna para operaciones de esa naturaleza. [...]

La tiranía de Sánchez Cerro, estigmatizada por todos los pueblos civilizados de la tierra no puede engañar a nadie sobre el triste sentido de maniobra política interna y mezquina que tiene su actuación diplomática, ambigua y desleal, de reconocimiento y, a la par, de desconocimiento de la fuerza obligatoria del tratado Salomón-Lozano. [...]

He querido tener esta charla con usted, amigo mío, aunque milite usted en campo político opuesto, o por lo menos distinto al mío, como un deshago de mi espíritu, entristecido por los oprobios del actual momento de la vida nacional; es usted comprensivo como todo hombre de talento superior, y por apasionado que sea su punto de vista, ha de convenir 
que sus amigos están jugando una carta muy peligrosa para el porvenir de la nacionalidad. No es mi ánimo iniciar una polémica epistolar con usted, y por eso le relevo del deber social y de amistad de darme respuesta. Ni siquiera le doy la dirección a la que podría dirigirme su carta de contestación o de aviso de recibo. Me bastará que por teléfono le manifieste a mi esposa haber llegado a las manos de usted la presente, que, para tomar las seguridades posibles, le remito certificada. No me sorprenderá que fuera, a pesar de todo, sustraída en el correo. [...] Conservo copia de ella, quizás si algún día [tuviera] usted tardío conocimiento de la existencia de este deshago de su viejo amigo.

Sin otro particular que desearle salud y ventura le estrecha la mano su amigo y servidor,

Clemente Palma (Riva-Agüero, 2010, pp. 84, 86, 88-89).

\section{Gestiones en Santiago y Lima para la edición del libro: Entorno a Ricardo Palma}

En las semanas posteriores a su llegada a Santiago de Chile, Palma visitó algunas de las instituciones culturales más importantes de la capital del Mapocho, y de modo particular la Biblioteca Nacional, dirigida entonces por Tomás Thayer Ojeda, quien tuvo la amabilidad de guiarlo por las salas del principal centro bibliográfico de ese país. En dicha visita, Palma pudo, por primera vez, conocer en persona al polígrafo don Guillermo Feliú Cruz, de reconocido prestigio en el mundo bibliófilo hispanoamericano. El propio Feliú haría mención de este encuentro con Palma a don José de la Riva-Agüero y Osma, en una extensa carta que le envía desde Santiago de Chile, el 14 de febrero de 1933 (Riva-Agüero, 1999, p. 57).

Luego de esta visita, Clemente Palma escribió a su hermana Angélica en Lima para lograr que, por la intersección del 
flamante embajador del Perú en Chile don Pedro Manuel Irigoyen Diez Canseco, la Universidad Nacional Mayor de San Marcos pagara la edición íntegra del libro de Feliú, pues consideraba que era una investigación notable acerca de los años en los que el padre de las Tradiciones peruanas estuvo desterrado en Chile (1860-1862) ${ }^{12}$. Con ese propósito, Irigoyen gestionó el pedido a la Decana de América, pero dada la coyuntura política del momento, el gobierno sanchecerrista consideró que no era oportuno que un personaje vinculado directamente a un deportado político -Clemente Palma- recibiera cualquier tipo de ayuda, sin importar que ese personaje a homenajear fuera don Ricardo Palma, quien tanto había hecho por elevar culturalmente el nombre del Perú (Adriazola, 2013, p. 416). Feliú, al tomar noticia de esta negativa, expresa entristecido a Riva-Agüero:

En la seguridad de que el Gobierno o la Universidad habrían de contribuir con su óbolo [...] emprendí la publicación. Hubo un error de cálculo en el número de pliegos. Se calcularon 11 y la obra excede al triple de lo que se creyó. He aquí, mi respetado señor, la dolorosa situación en que me encuentro: sin poder cancelar por mi pobreza, un libro que interesa al Perú, que está hecho con todo amor y cariño y que es la manifestación de un chileno a una de las glorias más puras y altas de ustedes. ¿Cómo es posible que el Gobierno y la Universidad, por muy fuertes que sean las asperezas políticas, no puedan comprender el sentido de cultura, de honor, de gloria, que entraña para el Perú el reconocimiento de un extranjero? (Riva-Agüero, 1999, p. 58).

12 En carta de Angélica Palma a Riva-Agüero, datada en «Casa de usted» [Lima] 18/12/1932, le cuenta lo que su hermano le ha expresado desde Chile: «Clemente $[\ldots]$ me dice que no sabe si le causa orgullo o envidia el que tan importante trabajo se deba a pluma extranjera» (Riva-Agüero, 2010, p. 61). 
El embajador Irigoyen como una forma de ayudar a don Guillermo Feliú Cruz, tan pronto como arribó a la capital del Mapocho, le hizo entrega de \$ 3153 pesos, con el propósito de que empezara ya la impresión del libro, con la esperanza de que lograría reunir el dinero faltante y así completaría el pago total de la edición. Lamentablemente, sus gestiones al final fueron infructuosas, pues el gobierno del general Sánchez Cerro no tenía el mayor interés en el centenario palmista, so pretexto de estar preocupado en asuntos de mayor envergadura en el orden internacional. Es entonces que Angélica Palma le pide a Guillermo Feliú escriba a su amigo el doctor José de la RivaAgüero y Osma, quien tenía ya conocimiento de la situación, y era la última esperanza que les quedaba para que el libro se editara. En ese contexto, Feliú expresa a Riva-Agüero estas sinceras y humildes palabras:

Debo hablarle con entera franqueza. Si yo hubiese previsto el género de dificultades que se han presentado, por nada habría hecho imprimir el libro. Pero con la ayuda del señor Irigoyen y en la convicción absoluta del apoyo del Gobierno o de la Universidad, cometí el error de avanzar la obra. Soy reo de precipitación. Tampoco he solicitado para mí ninguna clase de honorario y estoy dispuesto a entregar los 500 ejemplares que se han tirado en la siguiente forma: 250 para usted y 250 para el señor Irigoyen. Creo que tanto usted, como el señor Embajador, a título de autor y de padre de este desdichado libro podrán concederme, cada uno 50 ejemplares. Por lo demás, el libro les será dedicado.

Lo que resta para cubrir totalmente la edición son ocho mil pesos chilenos que, reducidos a moneda peruana o dollares, significa una suma muchísimo menor que la que representa en la nuestra. Para mí, escritor, profesor y servidor público y caballero ante todo, me es doloroso tener que suplicar una ayuda que muy bien comprendo en el alto significado de usted como hombre culto y que sabe el valor de estas cosas, 
pero que me es profundamente dolorosa. Sin embargo, el ofrecimiento de usted compromete mi gratitud de tal manera que usted nunca llegará a comprenderlo y me habla muy alto del patriota y del escritor que, con su nombre y su obra, honra a su patria (Riva-Agüero, 1999, p. 59).

Finalmente, el libro de Feliú, titulado En torno de Ricardo Palma, pudo concretarse en las Prensas de la Universidad de Chile, a mediados del año 1933. Y como lo prometió anticipadamente su autor, la obra fue dedicada a las tres personas fundamentales que coadyuvaron a su realización. La ofrenda escrita reza:

Inscribo aquí tres nombres peruanos ilustres en el recuerdo de la amistad literaria: el de don José de la Riva Agüero y Osma, Presidente de la «Sociedad Amigos de Ricardo Palma» y el de don Pedro Irigoyen, Embajador del Perú en Chile, a cuyos esfuerzos generosos y desinteresados, débese la publicación de esta obra. Y también el de don Clemente Palma, virtuoso exiliado de su patria entre nosotros, hijo del tradicionista, que alentara al autor a dar forma de libro a un manuscrito que parecía condenado al olvido (Feliú, 1933, p. 9).

\section{A modo de conclusión}

Clemente Palma y José de la Riva-Agüero, contemporáneos por un lapso de 59 años, son dos personalidades señeras de las letras nacionales, cada una con su estilo y óptica propia de acuerdo a la condición social y circunstancias que les tocó vivir. RivaAgüero conoció a Clemente cuando este frisaba los 21 años y era «Conservador» de la Biblioteca Nacional del Perú, repositorio al cual Riva-Agüero acudió desde su infancia como lector habitual, y siendo ya universitario, visitó de continuo sus salas para consultar ávidamente los libros e infolios que necesitaba para sus investigaciones. Pero lo más grato de esa época debe haber sido, 
sin lugar a dudas, sostener largas y amenísimas tertulias con los Palma. El clima de confianza entre ellos se afianzó con los años, y el respeto mutuo creció por igual, lo cual se prolongaría hasta antes del inicio del segundo gobierno de Augusto B. Leguía (19191930). El inicio del Oncenio leguiista, marcó un tiempo nuevo en la comunicación entre Clemente y Riva-Agüero que hasta entonces había sido cordial y fluida. Mucho tuvo que ver en ella el autoexilio del polígrafo peruano en Europa; la desaparición física de don Ricardo acaecida en octubre de 1919; Clemente, de haber sido por varios años opositor acérrimo a Leguía, se volvió su más férreo defensor en la tribuna parlamentaria y periodística. El término del régimen de la Patria Nueva en 1930 no reestableció plenamente la antigua amistad entre Riva Agüero y Clemente, a pesar de que coincidieron en varios proyectos e instituciones como, por ejemplo, la Academia Peruana de la Lengua. Siempre quedaron resquicios de duda y desconfianza sobre todo por parte del polígrafo peruano. El balance final de esta amistad, signada por el afecto y la malquerencia, perduró por casi medio siglo bajo la sombra espiritual de ese árbol añejo y frondoso que fue don Ricardo Palma, el genio creador de las Tradiciones peruanas.

\section{Referencias bibliográficas}

Academia Peruana de la Lengua. (1967). Reproducción facsimilar de «Los Primeros Estatutos de 1887». En Boletín de la Academia Peruana de la Lengua, núm. 1, Lima, pp. 59-65.

Adriazola Silva, J.C. (1991). La revista Variedades y las crónicas «De jueves a jueves» de Clemente Palma sobre el conflicto peruano chileno de Tacna y Arica (1908-1929). (Tesis inédita de periodismo), Piura: Universidad de Piura. . (2000). Clemente Palma (1872-1946). Las décadas de un escritor del Modernismo. (Biografía inédita). Piura, Biblioteca y Archivo Colección Adriazola. 
. (2009). «Clemente, el primogénito de don Ricardo Palma». En Aula Palma $\mathrm{N}^{\circ}$ VIII, Lima, Instituto Ricardo Palma de Universidad Ricardo Palma, pp. 213-234.

. (2013). «Don Ricardo y su hijo Clemente, dos desterrados políticos en tierras del Mapocho». En Aula Palma $\mathrm{N}^{\circ}$ XII, Lima, Instituto Ricardo Palma de Universidad Ricardo Palma, pp. 375-427.

Basadre, J. (1971). Introducción a las bases documentales para la Historia de la República del Perú con algunas reflexiones. Lima, P.L. Villanueva. T. II, Cap. XII, p.621.

. (1983). Historia de la República del Perú 1822-1933. 7 ed., 11

t. Lima: Editorial Universitaria.

Chirinos Soto, E. (1982). Historia de la República 1821-1982. 2da. ed. Lima: Editorial «Minerva».

Feliú Cruz, G. (1933). En torno a Ricardo Palma. 2 t. Santiago de Chile: Prensas de la Universidad de Chile.

Flores-Zúñiga, F. (2019). Ricardo Palma y la tribuna parlamentaria. El tradicionista senador (1868-1873). Lima: Fondo Editorial del Congreso del Perú.

Holguín Callo, O. (2001). «Palma y Riva-Agüero: calas a su amistad». En Páginas sobre Ricardo Palma, pp. 183-210. Lima: Universidad Ricardo Palma.

Jiménez Borja, J. (1966). José de la Riva Agüero. [Cuarta Serie Biblioteca Hombres del Perú XL] , pp.5-64. Lima: Editorial Universitaria.

Kapsoli, W. (comp.). (2002). Unamuno y el Perú. Epistolario, 19021934. Lima: Editorial Universitaria de la Universidad Ricardo Palma y Universidad de Salamanca.

Miró Quesada, A. (1967). «Los ochenta años de nuestra Academia». En Boletín de la Academia Peruana de la Lengua, núm. 1, Lima, pp.27-47.

Palma, C. (1912). «De jueves a jueves». En Variedades, 16 de marzo, núm. 211.

. (1926). «¿Cómo se inició Ud. en el Periodismo?». En Variedades, Lima, 16 enero, núm. 933. 
Palma, R. (2006). Epistolario General (1905-1919). T. VIII, vol. 3. Lima: Editorial Universitaria de la Universidad Ricardo Palma.

Real Academia Española (1947). Diccionario de la Lengua Española. Madrid: Espasa Calpe.

Riva Agüero y Osma, J. (1937). «Discurso de José de la Riva Agüero». En Angélica Palma. Lima, Sociedad Amigos de Palma, C.I.P., pp. 27-41.

- (1962a). Carácter de la Literatura del Perú Independiente. Estudios de Literatura Peruana. Obras Completas I. Lima: Instituto Riva Agüero de la Pontificia Universidad Católica del Perú.

. (1962b). Del Inca Garcilaso a Eguren. Estudios de

Literatura Peruana. Obras Completas II. Lima, Instituto Riva Agüero de la Pontificia Universidad Católica del Perú.

(1999). Epistolario Fabián-Guzmán. Obras

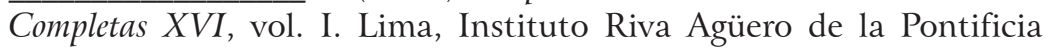
Universidad Católica del Perú.

. (2000). Epistolario Habich-Kuczynsky. Obras Completas XVII. Lima: Instituto Riva Agüero de la Pontificia Universidad Católica del Perú.

- (2003). Epistolario La Rosa- Llosa. Obras

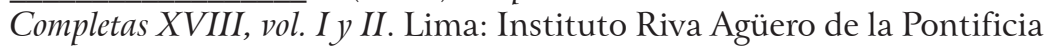
Universidad Católica del Perú.

. (2005). Epistolario Macavilca-Mústiga. Obras Completas XIX, vol. I. Lima: Instituto Riva Agüero de la Pontificia Universidad Católica del Perú.

. (2007). Epistolario Nachbin-Oyague y Joyero. Obras

Completas XX. Lima: Instituto Riva Agüero de la Pontificia Universidad Católica del Perú. . (2010). Epistolario Pacheco-Quiroz. Obras Completas XXI, vol. I. Lima: Instituto Riva Agüero de la Pontificia Universidad Católica del Perú. 